\title{
Investigations on Reinforced Concrete Corner Joints Under Bending Moment
}

\author{
Er. Parry Anees Ahmad \\ Research Scholar, Dept. of Civil Engineering. \\ Indo Global Group of Colleges, \\ Abhipur, Mohali, India
}

\author{
Er. Manjit Kaur ${ }^{1}$, Er. Hema Rani ${ }^{2}$ \\ ${ }^{1,2}$ Asst. Prof.Dept of Civil Engineering, \\ Indo-global group of Colleges. \\ Abhipur, Mohali, India.
}

\begin{abstract}
The results of the investigation of the behavior of planar reinforced concrete opening corner joints made up of plain and steel concrete are presented and discussed. Conventional arrangements of detailing corner rebars have been shown to be structurally inadequate and an innovative but simple detailing of opening corners has been proposed which gave corner efficiencies in the range of 90 to $95 \%$. The mechanics of opening corners were studied with the help of an assumed length of the critical diagonal crack and a simplified distribution of tensile stress at imminent cracking and it is shown that for optimum performance corner joints should be kept lightly reinforced with the amount of reinforcement being preferably less than $\mathbf{0 . 4 7 \%}$.However, for practical considerations, it has been shown that even at $0.76 \%$ of steel content, corner efficiencies of about $90 \%$ may still be obtained with the recommended detailing. Limited number of tests indicate that diameter of tension reinforcement has an insignificant effect on corner efficiency.
\end{abstract}

Key Words: Open corners, Conventional detailing, Recommended detailing.

\section{INTRODUCTION}

The beams and columns in a framed structure are designed based on simple element theories as the design principles for these basic elements are well understood. The same theory is invariably extended to the design of joints connecting these basic elements. The beam face of a joint is designed as a beam and the column face of the joint is designed as a column. The assumption that the joint is rigid, is probably an over simplification and may have been made for the purpose of design convenience. In fact, the behavior of joints is quite complex and thus the reinforcement detailing in the joints is very crucial for the satisfactory structural performance of joints. Unsafe design and detailing within joint region jeopardizes the entire structure, even if other structural members conform to design requirements. It has been confirmed in the previous studies that the performance of opening joints are more critically influenced by the detailing of reinforcement than those joints subjected to closing moments. This paper deals with the change in detailing arrangements of open corners so that efficiency may be improved.

Key Words: Behavior of Joints, Closing Moment.

\section{LITERATURE REVIEW}

Prakash Rao (1995) has emphasized the critical influence of detailing on the behavior of opening corners. Depending upon the size of framing members, two types of detailing arrangements were recommended for lightly reinforced (Steel content $<1 \%$ ) opening corners. For corner, where the depth of any of the framing member was up to $500 \mathrm{~mm}$, a detailing consisting of overlapping U-bars at the corner similar to the one suggested by Nilsson (1973) was recommended. For corner, where the depth any of the framing members was more than $500 \mathrm{~mm}$, it was recommended to provide radial hoops along the diagonal of opening corners. Singh and Chaturvedi (1997) reported that the efficiency of poorly detailed joints subjected to opening moments may be as low as $30 \%$, however, when detailed properly, the efficiency of the joints is improved significantly. They suggested that strut and tie model (STM) method can be satisfactorily used for proper detailing of reinforcement in the corner joints. Pillai and Menon (1998) proposed a detailing arrangement for opening corners where in the flexural reinforcement from one of the framing members was taken well into the corner and anchored in the compression zone of the adjacent member and vice-versa. This detailing was provided with additional splay steel (50\% of main steel) at the re-entrant corner and radial hoops along the corner. However this detailing would result in congestion of reinforcement in the joint. Abdul-Wahab and Salman (1999) investigated the effect of corner angle on the efficiency of reinforced concrete joints under opening bending moments. Twelve specimens with two reinforcement details and the included angle varying from 60 degree to 180 degree, were tested. It was concluded that corner efficiency was significantly influenced by the corner angle. The minimum efficiency was observed for the corner angle of 120 degree. Further, the use of splay steel at corner significantly improved the corner efficiency in the range of 56 to 100degree for different corner angles. Dhar and Singh (2004) investigated the effect of chamfer as well as reinforcement detailing on strength and behavior of opening corners. Four Specimens with detailing system comprising of loop steel and inclined bars with different amount of chamfer size provided at inner corner were investigated. In the first specimen no chamfer was provided and chamfer sizes of 60 $\mathrm{mm}, 120 \mathrm{~mm}$ and $180 \mathrm{~mm}$ were adopted for other specimens. It was observed that cracking in the corner region reduced with increase in chamfer. Failure load and joint efficiency increased with increase in chamfer. Inclined bar at re-entrant corner gets more lever arm and loop steel gets additional anchorage due to presence of chamfer. They also studied the stress variation in joint by 
linear finite element analysis and concluded that overall stress level in the corner decreased with increase of chamfer size. It was suggested that a chamfer of size equal to the thickness of framing member may be used in corner joints subjected to opening moments.

\section{OBJECTIVE OF THE STUDY}

- Experimental investigation of the performance of opening corner joints reinforced with three commonly used detailing arrangements. On the basis of observed behavior, an improved but practical detailing of opening corners has been suggested and its structural performance has also been investigated.

- Comprehensive investigation of the performance of the proposed detailing arrangement in terms of the effect of amount of tension reinforcement, compression reinforcement and splay reinforcement on the opening corner behavior.

- Analytical prediction of structural response of opening corner joints and comparison of experimental and theoretical results.

\section{METHODOLOGY}

The casting of the various specimens was done under laboratory conditions using standard equipment. Each casting batch consisted of one portal-type specimen and control specimens in the form of three $150 \mathrm{~mm}$ cubes for determining the concrete cube compressive strength, three $150 \mathrm{~mm} \times 300 \mathrm{~mm}$ cylinders for determining the split tensile strength and those beams of size $100 \mathrm{~mm} \times 100 \mathrm{~mm}$ x $500 \mathrm{~mm}$ for determining the flexural strength of concrete. For each batch, quantities of cement, fine aggregate, coarse aggregate and water by weight were kept ready in the required proportion. The specimens were stripped after 24 hours of casting, and since it was not possible to immerse the portal-type specimen for curing in fresh water because of their sheer size, they were cured in the laboratory by covering them with jute bags, which were kept moist by periodically sprinkling them with water. To maintain the same curing conditions as the portal- type specimens, the control specimens were also cured in a similar manner. Curing was carried out for 28 days after the day of casting. Before testing, the specimens were thoroughly cleaned and then white washed to make their surface visible for observation of cracks during testing. The load was applied using a hydraulic ram consisting of a jack connected to a pump unit. Since the opening moment on the corner was to be produced by a load applied at the free end of the vertical framing member, a specially fabricated loading arrangement consisting of a pair of stiff mild steel bearing plates tightly bolted to each of the vertical framing members, at their free ends, was used. Baty dial gauges with magnetic base were used to measure the deflections in the vertical framing members at the points of load application. The least count and stroke of these dial gauges was $0.01 \mathrm{~mm}$ and $25 \mathrm{~mm}$ respectively. DEMEC strain gauges of $100 \mathrm{~mm}$ gauge length were used for measuring concrete surface strains at selected locations along the corner diagonal of specimen. The least count of the gauge was 0.0001 inches. The gauge was used along with mild steel studs of $16 \mathrm{~mm}$ diameter and having a punch mark on one surface. The plain surface of each stud was pasted to the specimen by Araldite, a quick fixing solution. The punch mark on the stud was to accommodate the conical knob of the strain gauge.

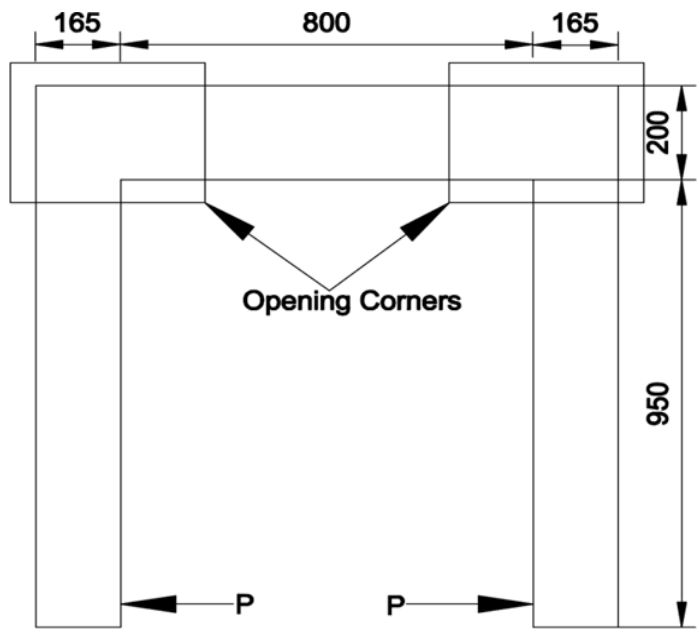

(All Dimensions are in $\mathrm{mm}$ )

Figure: Plan of Test Specimen

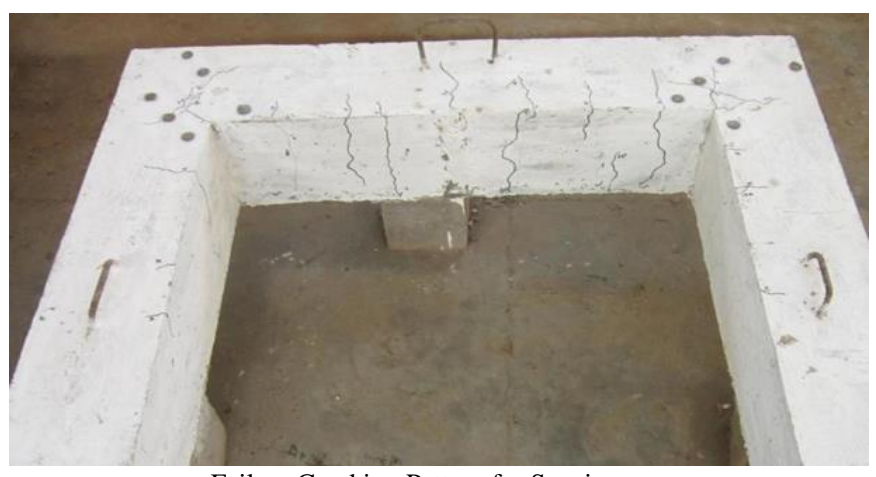

Failure Cracking Pattern for Specimen 
RESULT AND DISCUSSION

\begin{tabular}{|c|c|c|c|c|c|c|}
\hline $\begin{array}{r}\text { Specimen } \\
\text { Designation }\end{array}$ & $\begin{array}{l}\text { Crack Width } \\
\text { at } \\
0.5 \mathrm{M}_{\mathrm{UC}} \\
\text { (service } \\
\text { load) }\end{array}$ & $\begin{array}{l}\text { Crack } \\
\text { Width } \\
\text { Before } \\
\text { Failure } \\
\text { (mm) } \\
\end{array}$ & $\begin{array}{c}\text { Ultimate } \\
\text { Load }(\mathbf{k N})\end{array}$ & $\begin{array}{c}\text { Theoretical } \\
\text { Ultimate } \\
\text { Moment, } \mathrm{M}_{\mathrm{UC}} \\
\text { (kN-m) }\end{array}$ & $\begin{array}{c}\text { Test Failure } \\
\text { Moment } \mathbf{M}_{\mathrm{UT}}(\mathrm{kN}- \\
\mathbf{m})\end{array}$ & $\begin{array}{l}\text { Corner Efficiency } \\
\mathbf{M}_{\mathrm{UT}} / \mathbf{M}_{\mathrm{UC}} \mathbf{x 1 0 0}(\%)\end{array}$ \\
\hline SP1 & - & 0.40 & 6.50 & 10.23 & 5.40 & 52.78 \\
\hline SP2 & 0.20 & 0.95 & 8.60 & 10.24 & 7.14 & 69.74 \\
\hline SP3 & 0.25 & 1.05 & 10.40 & 10.22 & 8.58 & 83.97 \\
\hline SP4 & 0.30 & 1.15 & 11.50 & 10.21 & 9.55 & 93.52 \\
\hline
\end{tabular}

Test Results of Specimens with Different Detailing Arrangment

A comparison of the load deflection behavior and efficiency factors of specimens SP1, SP2, SP3 and SP4 given in Figure respectively, shows that the performance of specimen SP4 was considerably better when compared to others. Therefore, this detailing system was selected for further investigations.

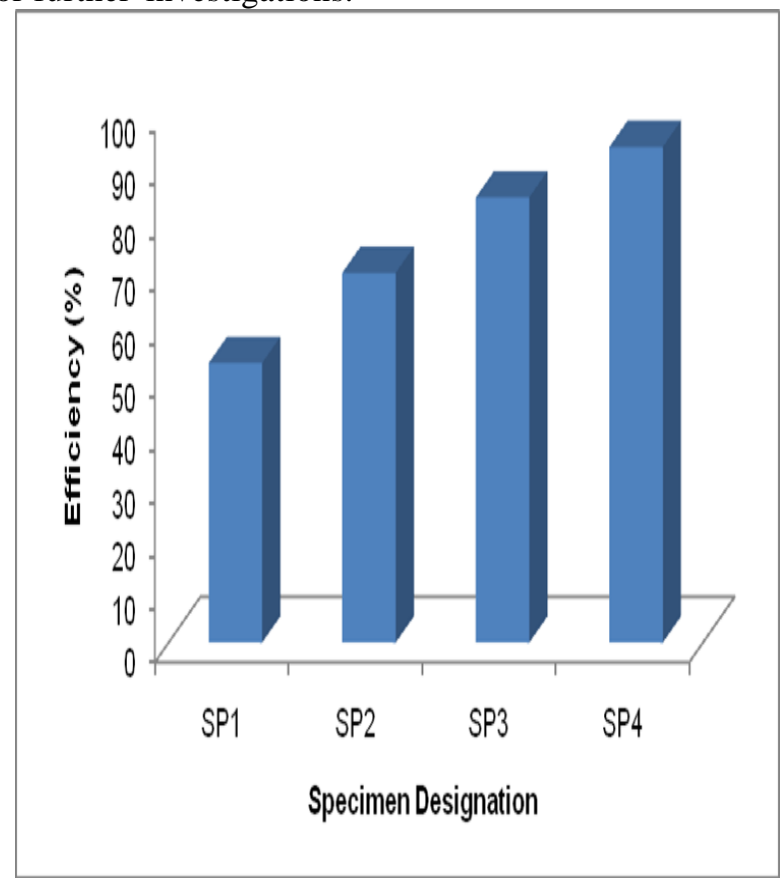

The load-deflection curve for specimen SP1 presented in Figure indicates a typical brittle failure. The mode of failure of specimen SP1 suggests that a mechanism to strengthen the corner diagonal in terms of shouldering the diagonal tensile force would result in higher efficiencies.

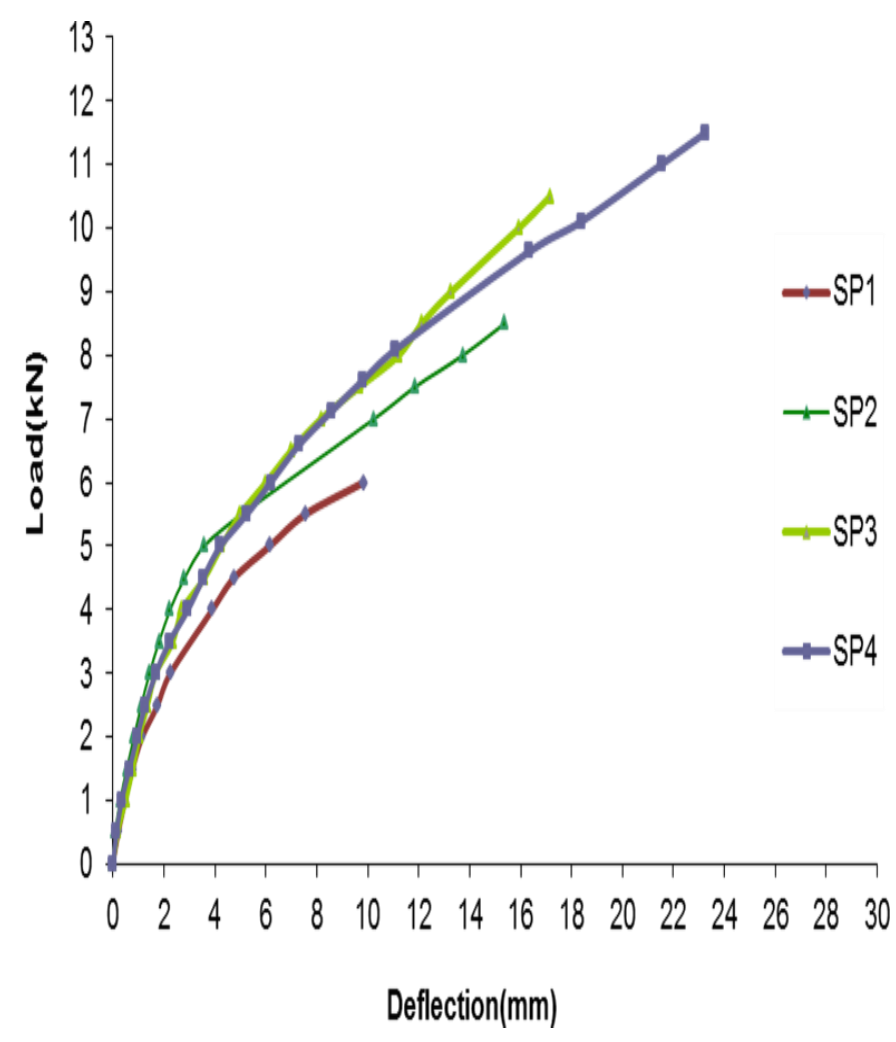

CONCLUSION

Efficiency factors significantly smaller than the ideal value of $100 \%$ were obtained for the corner joints detailed with two randomly selected reinforcement arrangements which are commonly used in practice. On further investigation, a relatively better efficiency factor of $84 \%$ was obtained in the specimen detailed with overlapping U-shaped bars spliced with the longitudinal reinforcement in the members framing into the corner.

An efficiency factor marginally in excess of $90 \%$ was obtained in the corner specimen detailed with a reinforcement arrangement which was conceived as a modification of detailing commonly used at construction sites. In this detailing, the main tension reinforcement of the framing members was extended to the far end of the corner and then bent in the corner joint as a 90 degree hooked extension.

$>$ Analysis of a typical corner joint shows that in the absence of any confinement of concrete, the structural capacity of the corner joint is controlled by the tensile strength of the 
concrete. Corner efficiency decreased from $94 \%$ to $82 \%$ as the amount of tension reinforcement in the detailing recommended in this investigation increased from $0.76 \%$ to $1.18 \%$. This observation reiterates the importance of keeping corner joints lightly reinforced.

\section{FUTURE SCOPE OF STUDY}

The structural behavior of opening corner joints can be investigated using High Performance Fibre Reinforced Concrete (HPFRC).

$>$ The comparative evaluation of the performance of opening corners detailed as per the recommendations of various national codes of practice may be carried out to explore the possibility of using fibrous concrete in the corners, wherever required.

\section{REFERENCES}

[1] Abdul-Wahab, H.M.S. and Ali, W.M. (1989), "Strength and Behaviour of Reinforced Concrete Obtuse Corners under Opening Bending Moments", ACI Structural Journal, V.86, No.6, Nov.Dec., pp.679-685.

[2] Abdul-Wahab, H.M.S. and Al-Roubai, A.A.M. (1998), "Strength and Behaviour of Steel Fibre Reinforced Concrete Corners under Opening Bending Moment", Magazine of Concrete Research, V.50, No.4, December, pp. 305-318.

[3] Abdul-Wahab, H.M.S. and Salman, S.A.R. (1999), "Effect of Corner Angle on Efficiency of Reinforced Concrete Joints under Opening Bending Moment”, ACI Structural Journal, V.96, No.1, Jan.-Feb., pp.115-121.

[4] ACI Committee 544 (1994), "Design Considerations for Steel Fibre Reinforced Concrete", ACI Manual of Concrete Practice, Part-1, ACI 544.4R-88.

[5] ACI 315-92 (1997), "Details and Detailing of Concrete Reinforcement", ACI Manual of Concrete Practice, Part-3, pp. 32-33.

[6] Babut, R. and Brandt, A.M. (1978), "The Method of Testing and Analysing of Steel Fibre Reinforced Concrete Elements in Flexure", RILEM Symposium-Testing and Test Methods of Fibre Cement Composites, Paper No. 7.11, pp.479-486 